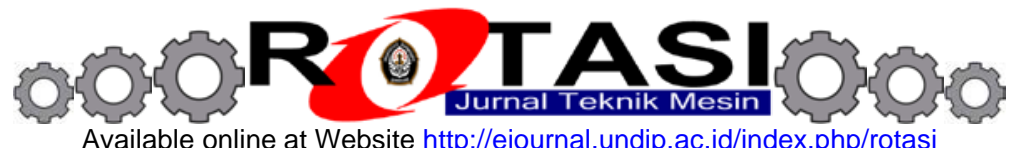

\title{
Torsional Stiffness Improvement of Truck Chassis Using Finite Elemen Method
}

\author{
*Ojo Kurdi ${ }^{\mathrm{a}}$, Roslan Abdul Rahman ${ }^{\mathrm{b}}$, Pakharudin Mohd Samin \\ Mohd Shukri Yob ${ }^{\mathrm{c}}$, Nantha Kumar Nadarajan ${ }^{\mathrm{c}}$, Ian Yulianti ${ }^{\mathrm{d}}$ \\ ${ }^{a}$ Mechanical Engineering Department, Universitas Diponegoro \\ Jalan Prof Sudharto, Tembalang, Semarang, Central Java, Indonesia \\ ${ }^{\mathrm{b}}$ Faculty of Mechanical Engineering, Universiti Teknologi Malaysia \\ 81310 UTM Skudai Johor Bahru, Malaysia \\ ${ }^{\mathrm{c}}$ Faculty of Engineering, Universiti Selangor, Selangor, Malaysia \\ Bestari Jaya Campus, Jalan Timur Tambahan Bestari Jaya Selangor Malaysia \\ ${ }^{\mathrm{d}}$ Physics Department, Universitas Negeri Semarang \\ Sekaran Campus, Gunung Pati, Semarang, Central Java, Indonesia \\ *E-mail: ojokurdi@ft.undip.ac.id
}

\begin{abstract}
This thesis deals with a study on the torsional stiffness of existing truck chassis and some others improved models by using finite element method. The objective of this study is to improve the torsional stiffness by design and to provide simulation of the deflection on the chassis. The problem on the chassis is the deflection on the chassis whereas higher displacement will affect the torsional stiffness of the truck. ABAQUS was used as it is a powerful engineering simulation tool based on the finite element method. The magnitude of torsional stiffness for existing and modified models were calculated based on data of deflection of each models which were obtained from the finite element simulation. The multi holes model was choosen as the best proposed model due to the highest of torsional stffness as comparison result among existing and modified models.
\end{abstract}

Keywords: torsional stiffness, finite element method, truck chassis

\section{Introduction}

Transportation industry plays a major role in the economy of modern industrialized and developing countries. The predominant goal for the design of a commercial vehicle for the economy during its use from acquisition until disposal (minimal life cycle), and it is important to know that more than $3 / 4$ of the cost do not include the purchase. However requirement of safety, handling and ride comfort are also to be satisfied. It is universally recognized that torsional stiffness is one of the most important properties of a vehicle chassis. This is a measure of the stiffness of a frame or chassis in twist. When driving on uneven road surfaces, the chassis frame is exposed to large torsional forces. The front section behind the cab is torsionally flexible, while the rear section at the rear axle or bogie is torsionally rigid. This torsional flexibility provides the chassis with good mobility at the same time as ensuring adequate strength. This term can be obtained by measurement or by computer simulation.

Many researchers carried out study on truck chassis. O’Neal Arant. M [1] had conducted study on effected of chassis torsional stiffness on the accuracy of the heavy vehicle. The aim of the study is to represent all the trailer models to extreme ends of the range of chassis torsional stiffness. The primary goal of the analysis was to assess the accuracy of rollover simulations, sublimit under-steer test were also performed to assess the sensitivity of vehicle simulation result to chassis flexibility. According to Michael O'Neal result, it clearly shows that the torsional flexibility of the chassis can significantly affect the accuracy of vehicle dynamics.

Another case study was presented by Sampo et.al [2], they analyze the chassis torsional stiffness that influence the vehicle dynamic. The objective of the paper is to introduce two analytical vehicle model that constitute an efficient tool for a correct evaluation of the main effect of the chassis torsional stiffness on vehicle dynamic. The modal takes account of chassis torsional stiffness for the evaluation of the lateral load transfer and by mean of the concept of the axle cornering stiffness, includes the effect of the tire nonlinear behavior. Kazua.A et.al [3] have investigated the torsional stiffness share rate of truck frame. The authors proposed a new parameters, "torsional stiffness share rate", that directly correlates the contribution of member torsional stiffness to frame torsional stiffness with the internal force of the members as to torsion of the truck frame.

Thompson et al.[4] had conducted study on torsional stiffness on Winston Cup chassis. The torsional stiffness of a vehicle chassis significantly affects its handling characteristic. In their work, a new twist fixture apparatus designed to measure the torsional stiffness of a Winston Cup series chassis described. Result from the validation showed that the fixture was able to predict the average stiffness of the standard to within about $6 \%$ of the analytically determined stiffness (with 95\% confidence). 


\section{1. $\quad$ Finite element method}

When modeling requirements call for detailed chassis torsion moment evaluations, the usual solution employed is to embed a full finite element model within the handling simulation model. This approach generally produces more accurate results than the other torsionally compliant chassis models as FEA models have many more degrees of freedom and can model the actual chassis deformation as opposed to simply approximating the deformation with a particular deformation mode shape. The suitable powerful engineering simulation program based on the finite element method is ABAQUS. A complete ABAQUS analysis usually consists of three distinct stages, preprocessing, simulation and pos-processing.

\subsection{Model of truck chassis}

The existing model is depicted in Figure 1. The model has length of $12.35 \mathrm{~m}$ and width of $2.45 \mathrm{~m}$. The material of chassis is ASTM Low Alloy Steel A 710 C (Class 3) with $552 \mathrm{MPa}$ of yield strength and $620 \mathrm{MPa}$ of tensile strength. The other properties of chassis material are tabulated in Table 1.

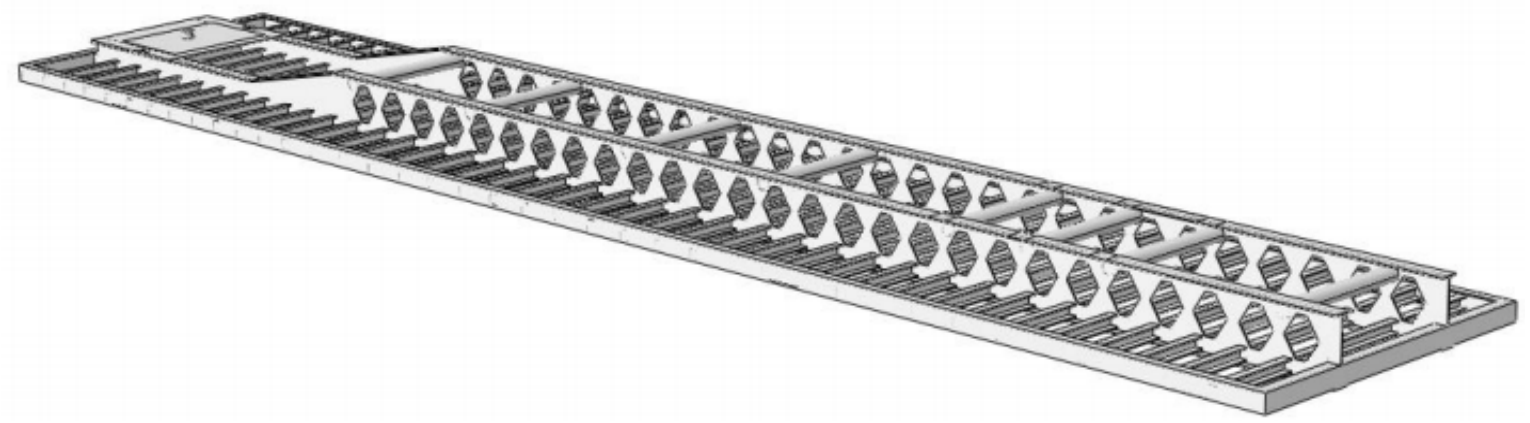

Figure 1. Existing Chassis Model

Table 1. Classification of truck chassis material

\begin{tabular}{ccccc}
\hline $\begin{array}{c}\text { Young Modulus } \\
\left(\mathbf{N} / \mathbf{m}^{2}\right)\end{array}$ & $\begin{array}{c}\text { Density } \\
(\text { tonne/mm }\end{array}$ & $\begin{array}{c}\text { Poisson's } \\
\text { Ratio }\end{array}$ & $\begin{array}{c}\text { Yield Strengh } \\
\left(\mathbf{N} / \mathbf{m}^{2}\right)\end{array}$ & $\begin{array}{c}\text { Tensile Strength } \\
\left(\mathbf{N} / \mathbf{m}^{2}\right)\end{array}$ \\
\hline $207 \times 10^{3}$ & $7.8 \times 10^{-9}$ & 0.3 & 550 & 620 \\
\hline
\end{tabular}

\subsection{Boundary condition}

The boundary conditions manager also used to view and manipulate the stepwise history of prescribed condition. Only one boundary condition applied to the chassis at fixed part of the truck. There are three fixed parts at both -side of the chassis where the tires and spring is attached to the chassis.

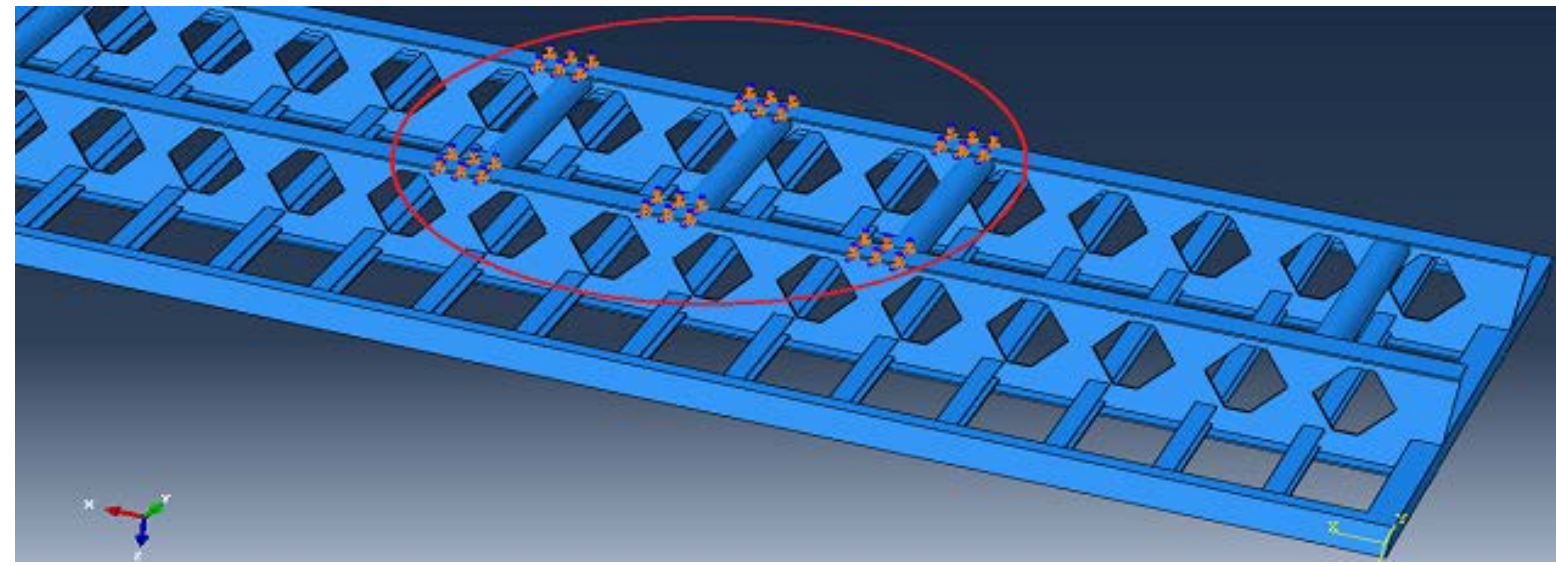

Figure 2. Boundary Conditions

\subsection{Load input}

Every truck chassis model is loaded by static forces at coupling section of the chassis. Various type of load used to obtain the required result from the simulation. Maximum load for the simulation is not more than $10,000 \mathrm{~N}$. Prescribed condition in Abaqus are a step dependent object, which means that the analysis step is specified in which they are active. 


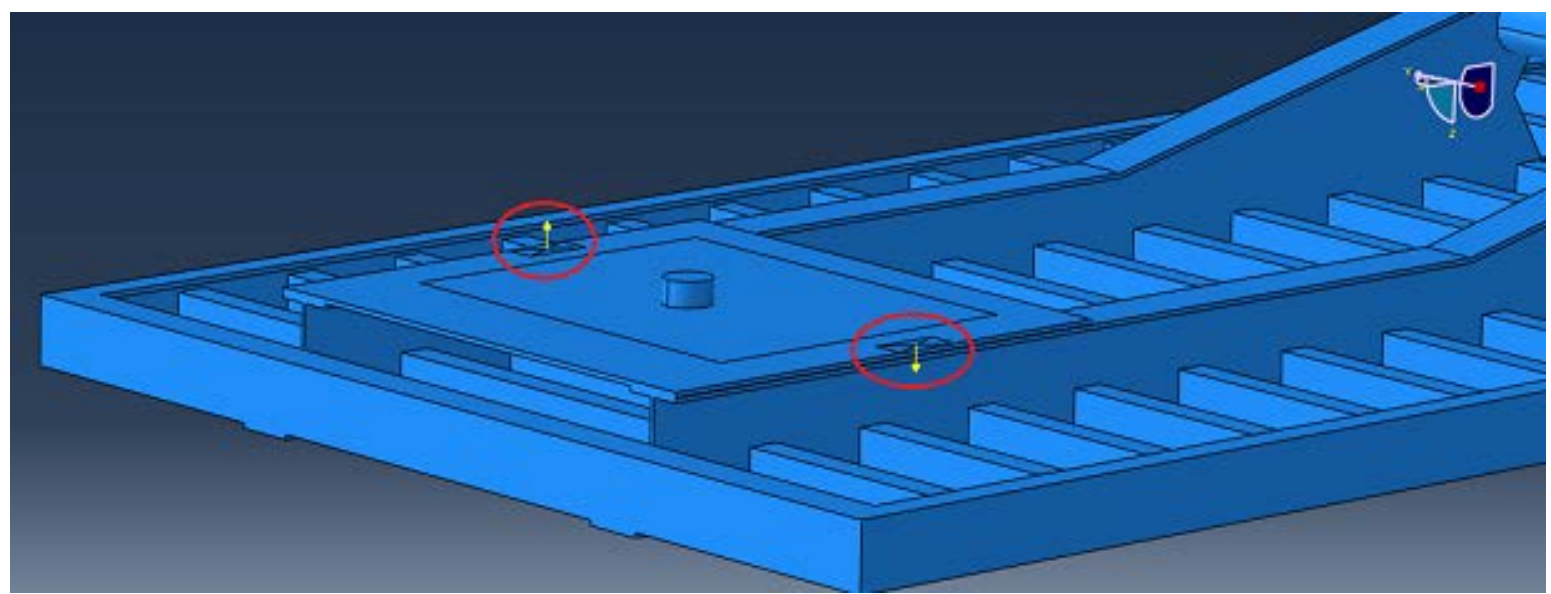

Figure 3. Load Input

\subsection{Modified models}

An improved model of truck chassis is modeled once the simulation has been done on the existing chassis. The improved model of the truck chassis should be able to provide better torsional stiffness then existing chassis. In order to compare with existing chassis, six other chassis have been modeled with various design. The type of chassis are Block model, Hole model, Multi- hole model, Empty model, arc model and reverse arc model. The figures of model are shown in the figure 4 below.

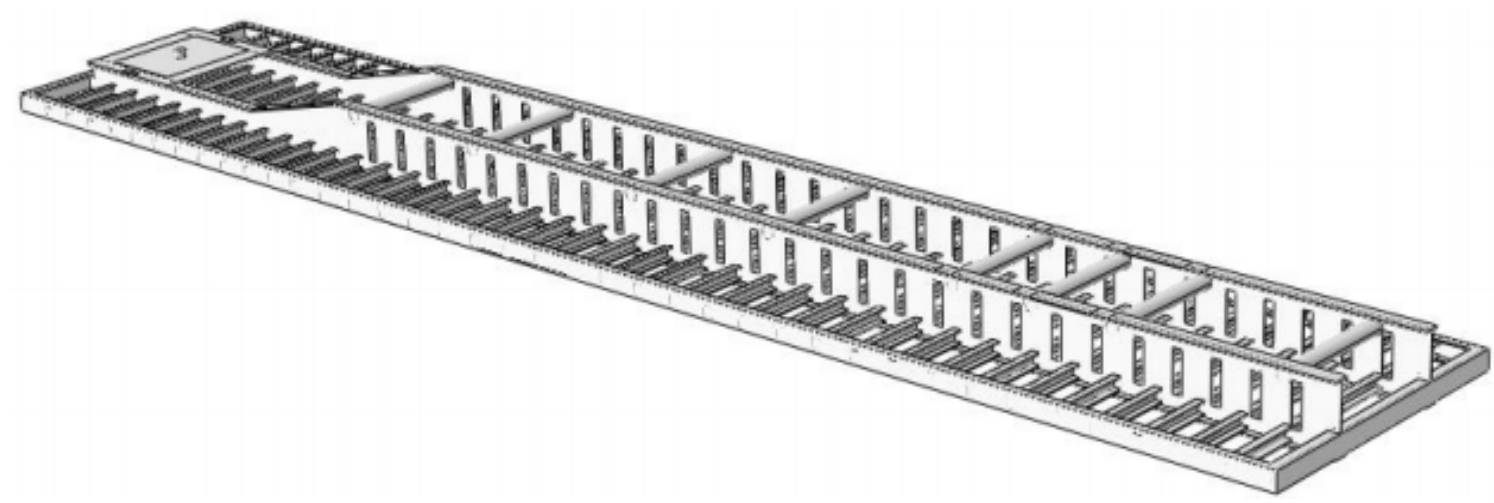

(a)

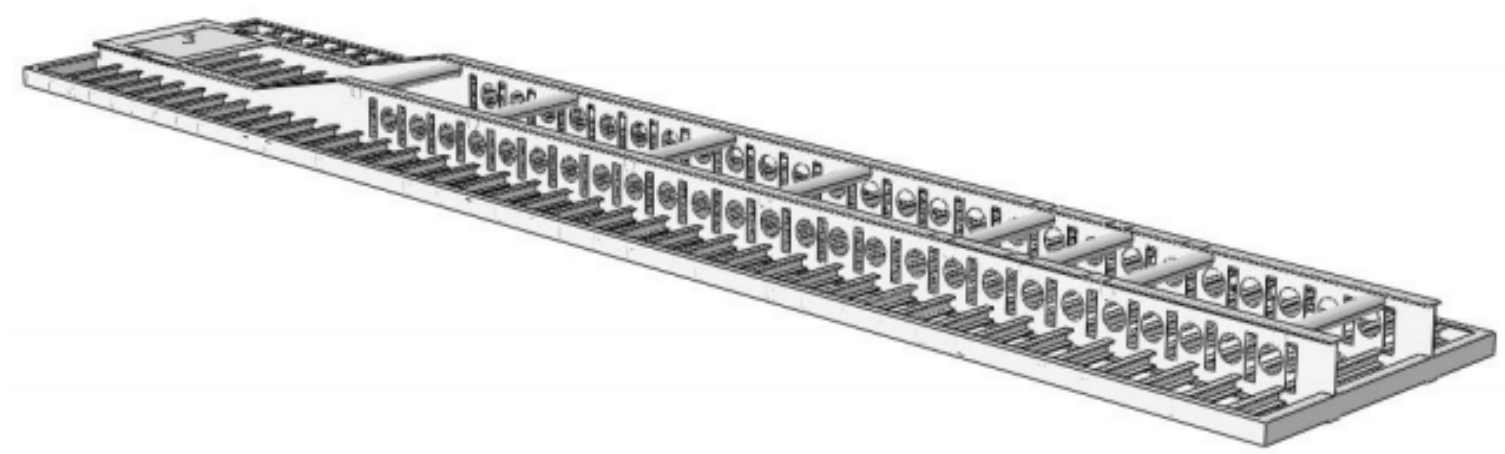

(b) 


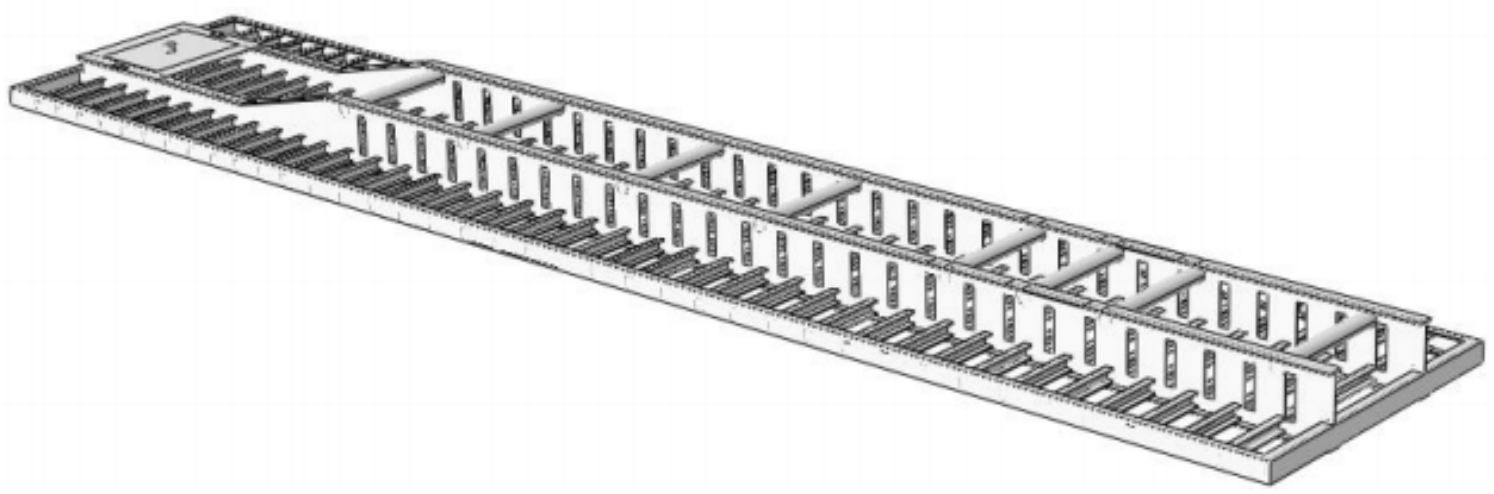

(c)

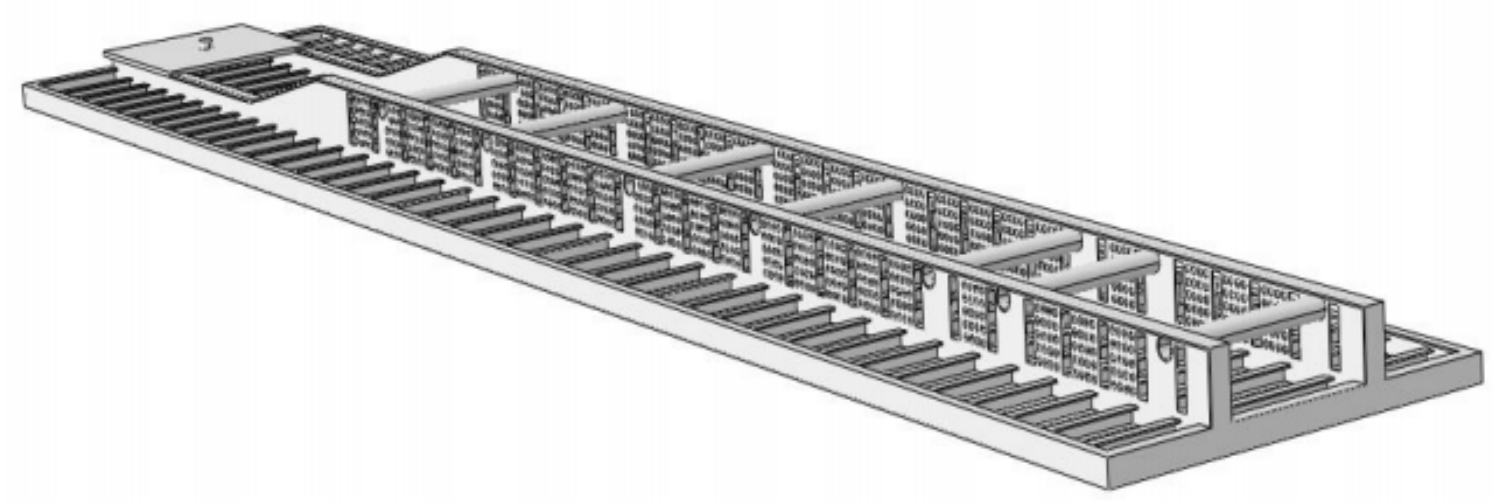

(d)

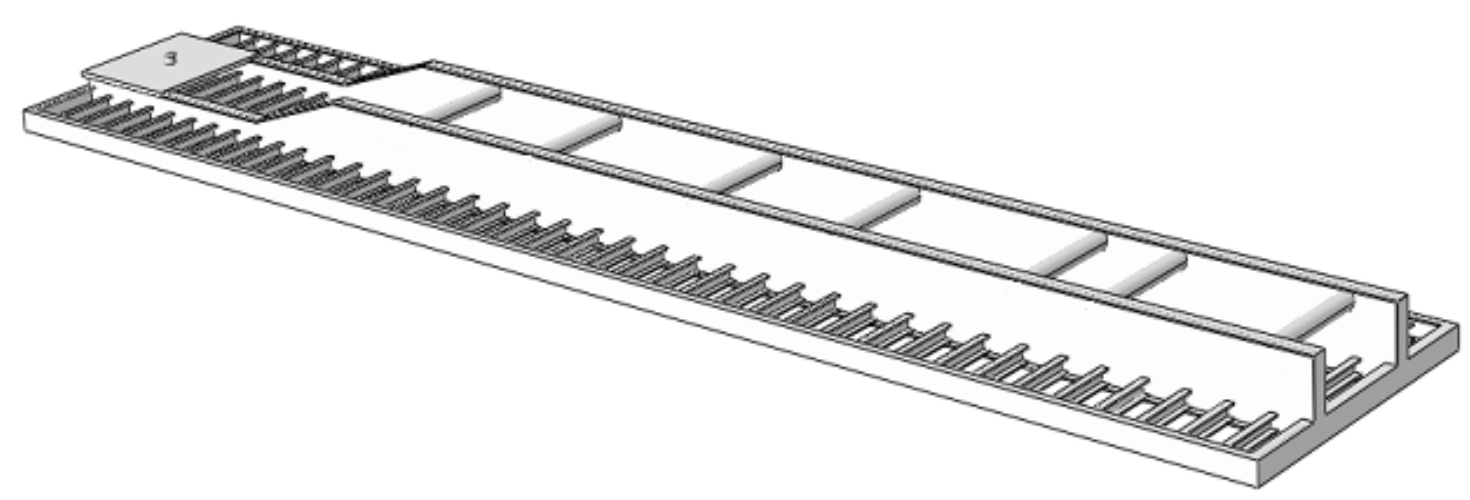

(e)

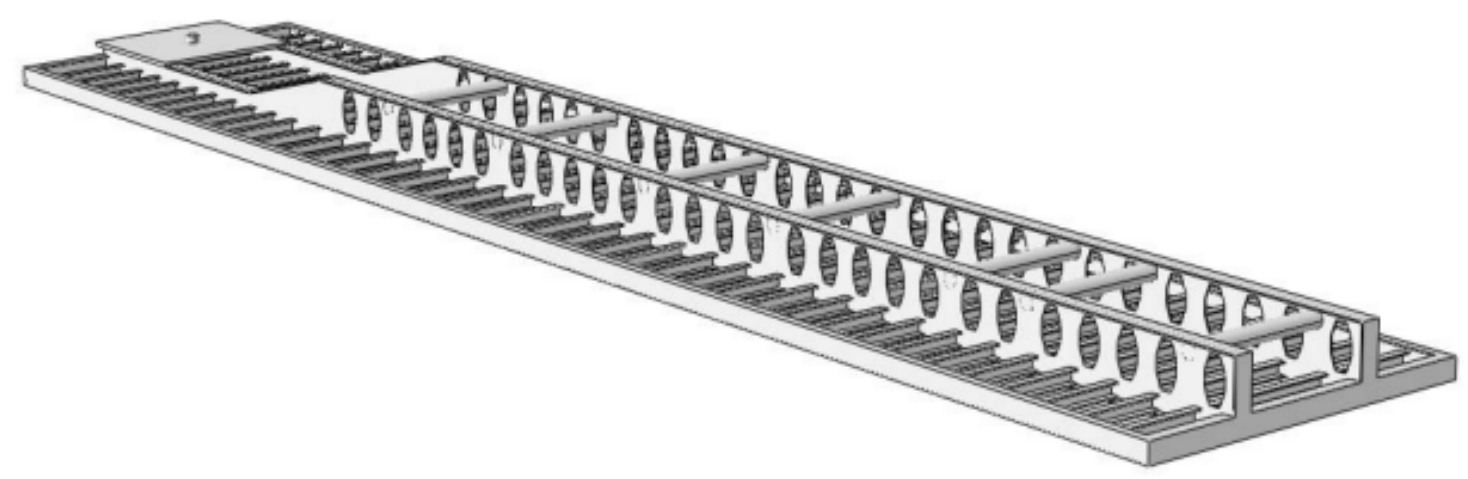

(f)

Figure 4. Modified models: (a) Block Model; (b) Hole Model; (c) Reverse Arc Model; (d) Multi hole Model; (e) Empty Model; (f) Arc Model 


\section{Result and discussion}

Motivated by the desire to make data available to increase the torsional stiffness of truck chassis models, the deflection as result of simulation were taken for the chassis of 6 various designed chassis to compare with existing models. Figure 5 showed the deflection of one model resulted from the simulaton. Table 1 showed the torsional stiffness value of all models according to applied load.

From the Tables 1, it shows that the average torsional stiffness of Existing model is $807186.32 \mathrm{Nm} / \mathrm{rad}$. Some other improved models are having better torsional result compare with Existing model. The higher torsional stiffness result given by Empty model which is $894207.94 \mathrm{Nm} / \mathrm{rad}$, followed by ARC (849271.25 Nm/rad),Hole (825139.66 $\mathrm{Nm} / \mathrm{rad}$ ) and finally Block which is $821808 \mathrm{Nm} / \mathrm{rad}$. Reverse arc and Multi holes chassis are having lower torsional stiffness compared to the Existing model. The torsional stiffness value of multi holes are only $9615.86 \mathrm{Nm} / \mathrm{rad}$ lesser than original chassis. But the Reverse Arc model stiffness has the lowest torsional stiffness which can cause dangerous to the truck.
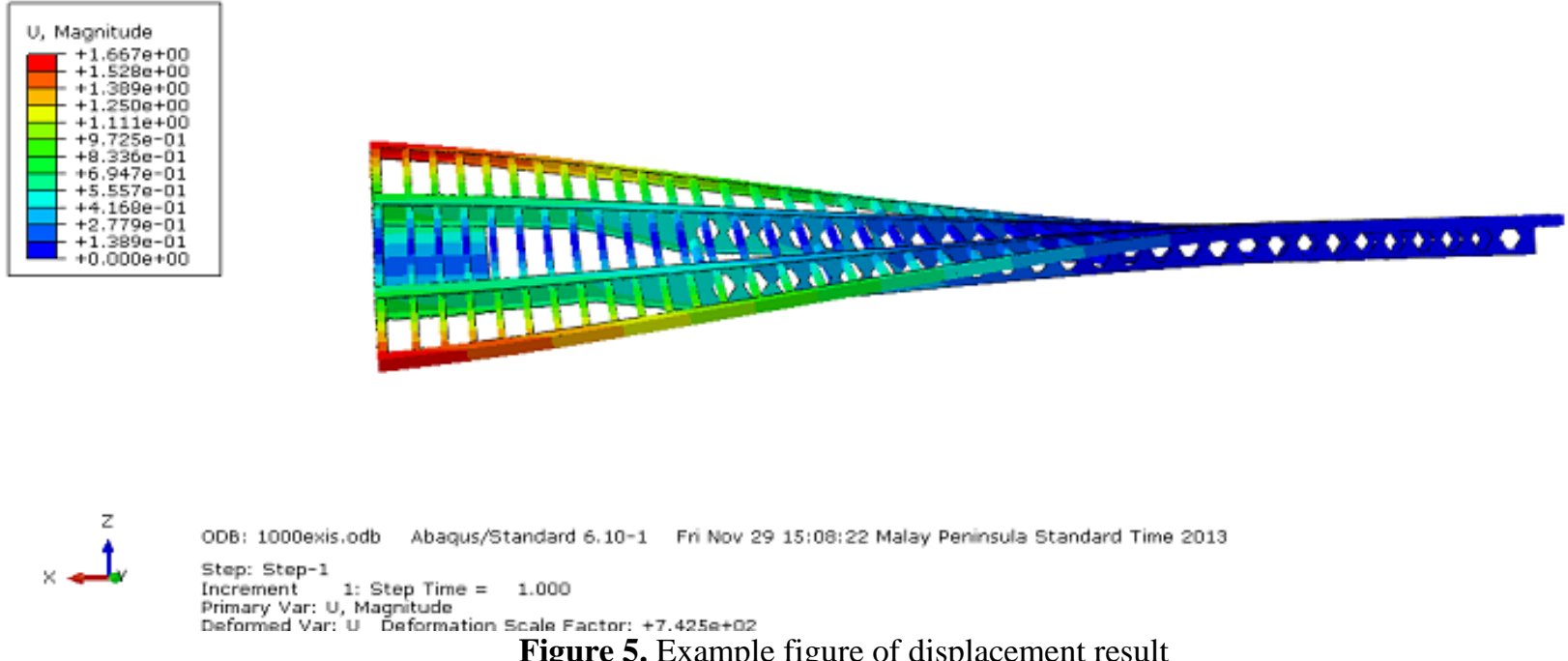

Table 2. Torsional stiffness of various models subjected 3 appll1ed load

\begin{tabular}{lccc}
\hline \multirow{2}{*}{ Chassis Model } & \multicolumn{3}{c}{ Torsional Stiffness (Nm/rad) } \\
\cline { 2 - 4 } & $\mathbf{1 0 0 0} \mathbf{~ N}$ & $\mathbf{5 0 0 0 ~ N}$ & $\mathbf{1 0 0 0 0 ~ N}$ \\
\hline Existing & 807235.05 & 807088.84 & 807235.05 \\
\hline Block & 821875.96 & 821673.8 & 821875.96 \\
\hline Hole & 825173.61 & 825071.75 & 825173.61 \\
\hline Multi holes & 797602.17 & 797507.00 & 797602.17 \\
\hline Arc & 849289.23 & 849235.27 & 849289.23 \\
\hline Empty & 894168.06 & 894287.69 & 894168.06 \\
\hline Reverse arc & 347712.64 & 347667.42 & 347486.67 \\
\hline
\end{tabular}

\section{Conclusion}

After an observation and analysis have been made, it is prove that the study on the torsional stiffness on the truck chassis by using finite element method is accomplished and the objective is achieved successfully. Through this study it can be concluded that the design of the chassis is the main factor in determining its torsional stiffness. From the result obtained, Empty Model and Arc Model is the most practicable and capable of improving the torsional stiffness of the truck chassis.

\section{Referensi}

[1] Arant, M. O., 2010, "The Effect of Chassis Torsional Stiffness on the Accuracy of Heavy Vehicle Understeer and Rollover Modelling”, Graduate School of Clemson University.

[2] Sampo, E., Sorniotti, A., \& Crocombe, A., 2010, Chassis Torsional Stiffness:Analysis of the Influence on Vehicle Dynamics, Research Studies Press Ltd.,Heartfortshire, England.

[3] AO, K., Niiyama, J., Matsui, T. \& Hara, K., 1991, Analysis of Torsional Stiffness Share Rate of Truck Frame, SAE technical paper, 4-5. 
[4] Thompson, L. L., Lamper, J. K. \& Law, E. H. (1998). Design of a Twist Fixture to Measure the Torsional Stiffness of a Winston Cup Chassis. Department of Mechanical Engineering, Clemson University.

\section{Acknowledment}

The authors would like to thank the Universiti Selangor (UNISEL) for the sponsorship. Our gratitude also goes to the CSM Laboratory and Vibration Laboratory, Faculty of Mechanical Engineering, Universiti Teknologi Malaysia for providing facilities and software package. 